\title{
Coherent-Synchronized Oxidation of Pyridine with Nitrous Oxide to 2,2- and 2,3-Dipyridil
}

\author{
Nagieva Inara ${ }^{2}$, Ali-zadeh Nahmad ${ }^{1}$ and Nagiev Tofik ${ }^{1,2 *}$ \\ 1. Nagiev Institute of Catalysis and Inorganic Chemistry, National Academy of Sciences of Azerbaijan, 113 H.Javid Av., Baku \\ 370143, Azerbaijani Republic \\ 2. Baku State University, 23 Z.Khalilov, Baku, Azerbaijan
}

\begin{abstract}
Synthesis of pyridine bases by way of relatively simple transformations with use of cheaper and available raw, is an actual problem. In this aspect the method in which the reactions of hydro-carbons oxidation are induced by nitrous oxide, is of scientific and practical interest. In the present work, the authors report the results of the experiments coherent-synchronized oxidation of pyridine with nitrous oxide to 2,2- and 2,3-dipyridyle.
\end{abstract}

Key words: Coherent-synchronized, nitrous oxide, oxidation, pyridine, 2,2- and 2,3-dipyridyle.

\section{Introduction}

As a result of corresponding investigations there have been established spheres of running coherent-synchronized oxidation of pyridine with the reaction of decomposition nitrous oxide.

There has been shown a high effectiveness of nitrous oxide that is able to direct the processes of pyridine oxidation to the side of selective formation of the purposed products.

The reactional system elaborated by us makes possible, according to the ordinary technology, to get a number of valuable monomers, that are used in many fields of industry and its has a number of advantages as compared with heterogenous-catalytical processes. There is no doubt that our proposed method is promising and could become one of the practical applications of the principle of the coherent-synchronized oxidation, as well as a new way of transformation of natural compounds in the preparations for, and possibly on a larger scale. But, for the transition to more complex nitrous-containing of heterocyclic compounds, similar in chemical

\footnotetext{
*Corresponding author: Tofik Murtuza Nagiev, professor, research field: Physical chemistry.
}

structure to the natural, must explore appropriate reactions involving individual their fragments.

\section{Experiments}

The reaction was performed in the flow quartz reactor of according methods [1-3], construction of which ensured the entry of nitrous oxide vapors into zone by a quartz tube, separately from pyridine. By another quartz tube preliminarily heated $\mathrm{P}$ (pyridine) in a gaseous state is feeder. The volume of the reaction zone made up $5.5 \mathrm{~cm}^{3}$. The reaction products were analyzed chromatographically.

Earlier [4-7] had suggested a fundamentally new method of oxidation of hydrocarbons (cyclohexane, cyclohexene, butane, butylene) in the gaseous phase at atmospheric pressure with nitrous oxide allowing most effectively to synthesize the desired products.

Considering the practical importance of pyridine and its derivatives the authors performed studies of the oxidation of pyridine in the gas phase at atmospheric pressure involving effective oxidant-nitrous oxide.

The qualitative determination of the reaction products composition was performed by chromatomass-spectroscopic method: "Agilent Technologies" (Germany). 


\section{Results and Discussions}

Coherent-synchronous oxidation of pyridine with nitrous oxide was studied in a wide range of process parameters: pyridine feed rate-0.948-1.896 $\mathrm{ml} / \mathrm{h}$, nitrous oxide feed rate $250-750 \mathrm{ml} / \mathrm{h}$. The reaction was carried out at various temperatures between 530-620 ${ }^{\circ} \mathrm{C}$.

The study of the coherent-synchronous oxidation pyridine in the temperature range 530-620 ${ }^{\circ} \mathrm{C}$ elucidated the kinetics of this reaction.

As is seen from Fig. 1, an increase of the temperature from $530{ }^{\circ} \mathrm{C}$ to $580{ }^{\circ} \mathrm{C}$ is accompanied by an increase of the yield of 2,2-DP (dipy-ridyle) (Fig. 1, curve 1) and 2,3-DP (dipy-ridyle) (Fig. 1, curve 2), what is associated with the growth of generation rate of the active centers-atomic oxide under thermal decomposition of nitrous oxide. The further increase of temperature from $580{ }^{\circ} \mathrm{C}$ to $620{ }^{\circ} \mathrm{C}$ leads to a sharp increase in the yield of 2,2-and 2,3-DP, at the same time increases and the conversion of pyridine. It is probably connected to that at the chosen contact times the concentration of atomic oxide increases and this leads to an increase in the number and amounts of byproducts-2,4-DP-3.56\%, 2-piridone-1.05\%, 4-piridone- $0.09 \%, \quad 2,2-\mathrm{DP} \quad \mathrm{N}$-oxide- $0.1 \%$, 2,2,6,2-terpyridyle-5.1\%. While at $530{ }^{\circ} \mathrm{C}$

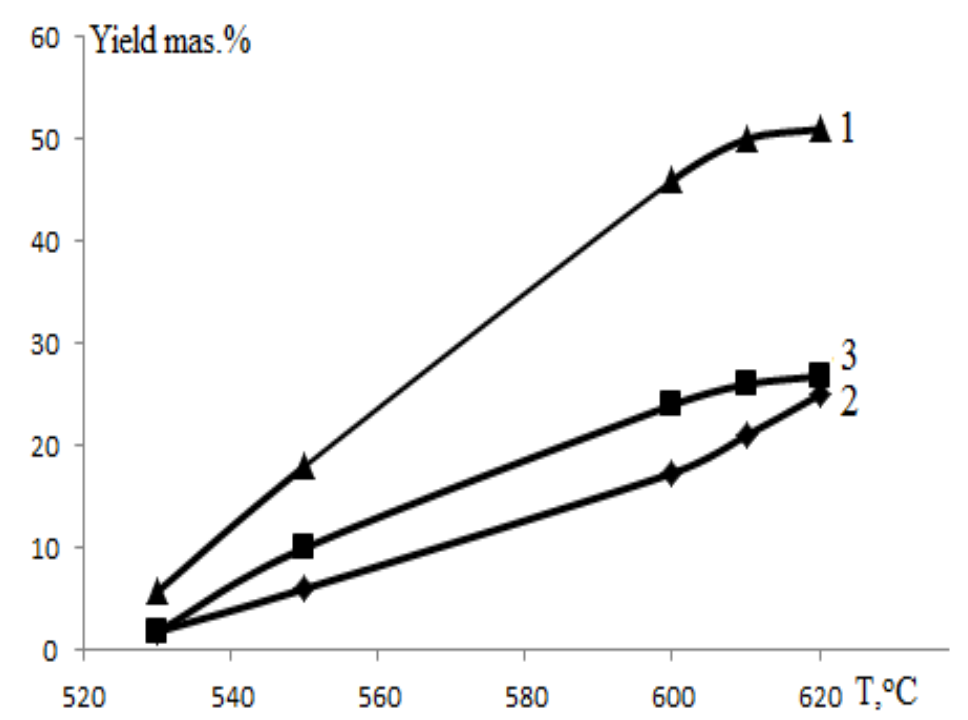

Fig. 1 The influence of temperature on yield of the reaction products: conversion (1), 2,2-dipyridyl (2), 2,3-dipyridyl (3), rate of supply of $P-1.896 \mathrm{~h}^{-1}$, rate of supply of $\mathrm{N}_{2} \mathrm{O}-250 \mathrm{~h}^{-1}$. byproducts were obtained with the following composition: $\quad 2,4-\mathrm{DP}-0.7 \%, \quad 4,4-\mathrm{DP}-1.32 \%$, 2,2-oxydipyri-dyle- $-0.2 \%$.

Indeed, as observed from the data of Fig. 2, the change of rate of $\mathrm{P}$ supply influences on 2,2- and 2,3-DP yield on rate of $P$ supply, i.e. contact time, with increasing supply rate from $0.95 \mathrm{~h}^{-1}$ to $1.42 \mathrm{~h}^{-1}$ the yield of 2,2- and 2,3-DP (Fig. 2, curves 2 and 3) rises. The further increase of rate of $\mathrm{P}$ supply from $1.42 \mathrm{~h}^{-1}$ to $1.89 \mathrm{~h}^{-1}$ does not significantly increase the yield 2,2- and 2,3-DP, decreases the conversion of $\mathrm{P}$ (Fig. 2, curve 1) and this leads to an decreases in the number and amounts of by-products.

Influence of nitrous oxide feed rate on the yield reaction products shown in Fig. 3. As is seen from curves in Fig. 3, on increasing on ate of $\mathrm{P}$ supply of nitrous oxide from $250 \mathrm{~h}^{-1}$ to $550 \mathrm{~h}^{-1}$, the yield of 2,2and 2,3-DP increases (Fig. 3, curves 2 and 3), what is quite probably, is connected to increase of the active centers atomic oxide in the volume (responsible for accumulation of 2,2- and 2,3-DP). The further increase of rate of nitrous oxide supply from $550 \mathrm{~h}^{-1}$ to $710 \mathrm{~h}^{-1}$ it leads to a slight increase in of the target products (Fig. 3, curves 2 and 3), due to the decrease of contact time. There has been some reduction in the conversion of $\mathrm{P}$ (Fig. 3, curve 1). 


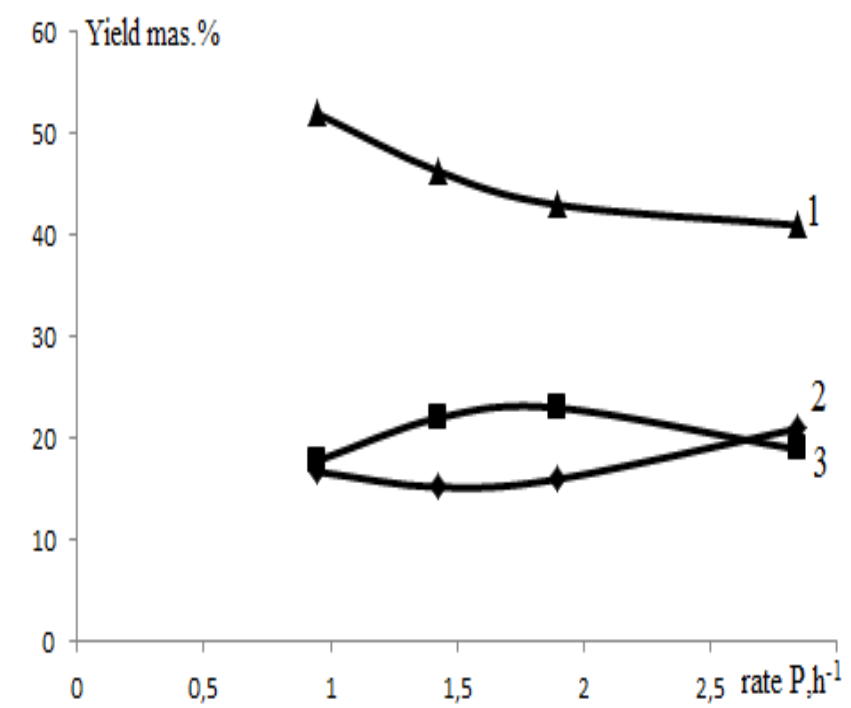

Fig. 2 The influence of vol. rate of $P$ supply on yield of the reaction products: conversion (1), 2,2-dipyridyl (2), 2,3-dipyridyl (3), $T=600{ }^{\circ} \mathrm{C}$, rate of supply of $\mathrm{N}_{2} \mathrm{O}-250 \mathrm{~h}^{-1}$.

The reaction is carried out in the temperature range 530-620 ${ }^{\circ} \mathrm{C}$. Experimental studies have shown that the oxidation reaction of pyridine with nitrous oxide proceeds to form 2,2- and 2,3-DP. Small amounts were detected 2.2': 6'.2" terpiridil to $4.6 \mathrm{wt} . \%, 2,2-$ oxidipyridyl to 2.09 wt.\%, 4,4-DP to $3 \mathrm{wt} . \%$. As a positive factor it should be noted that observed stable formation of 2,2- and 2,3-DP in all experiments:

As a result of studies, it was found that coherent-synchronized oxidation of pyridine with nitrous oxide leads mainly to the formation of 2,2- and 2,3-DP in a conversion pyridine $40-45$ wt. $\%$.

Experimental investigation was carried out with a view to of establishing the kinetic laws of the process of the homogeneous process of pyridine with nitrous oxide.

\section{Conclusions}

Experimentally investigated reaction of pyridine oxidation of nitrous oxide in the homogeneous conditions, in the gas phase, without the use of catalysts, at atmospheric pressure.

Installed region of the selective oxidation pyridine of nitrous oxide and was found the optimum conditions for obtaining valuable raw materials, which needed in petrochemical, chemical, pharmacological industries.
For the first time by oxidation of pyridine with nitrous oxide in homogeneous conditions was obtained 2,2- and 2,3-DP on the simplified technology. In the optimal mode yield of 2,2- and 2,3-DP was $23.0 \mathrm{wt} . \%$ and $25.4 \mathrm{wt} . \%$, respectively [8]. It is shown that in the system of coherent-synchronized of free-radical reactions of thermal decomposition of nitrous oxide and pyridine oxidation is carried out reaction dimerization of pyridine.

Thus, conducting the oxidation reaction of pyridine of nitrous oxide demonstrates the use of a new direction in the heterocyclic synthesis such as popular of compounds as the 2,2-, 2,3-, 4,4-dipyridyls, 2,2-oksidipyridyl, 2-py-ridone , 2,2: 6,2-terpyridine allows to obtain on their basis the new nitrogen-containing heterocyclic compounds.

The resulting novel substances are of some certain interest for the synthesis securities of pyridine bases, without the use of catalysts and under atmospheric pressure, as well as getting rid of the disadvantages of the same similarly catalytic reactions, determines the practical importance of this work.

Many synthesized of the compounds as described above may be used as monomers, which are required in the petrochemical, chemical and pharmaceutics industries. 


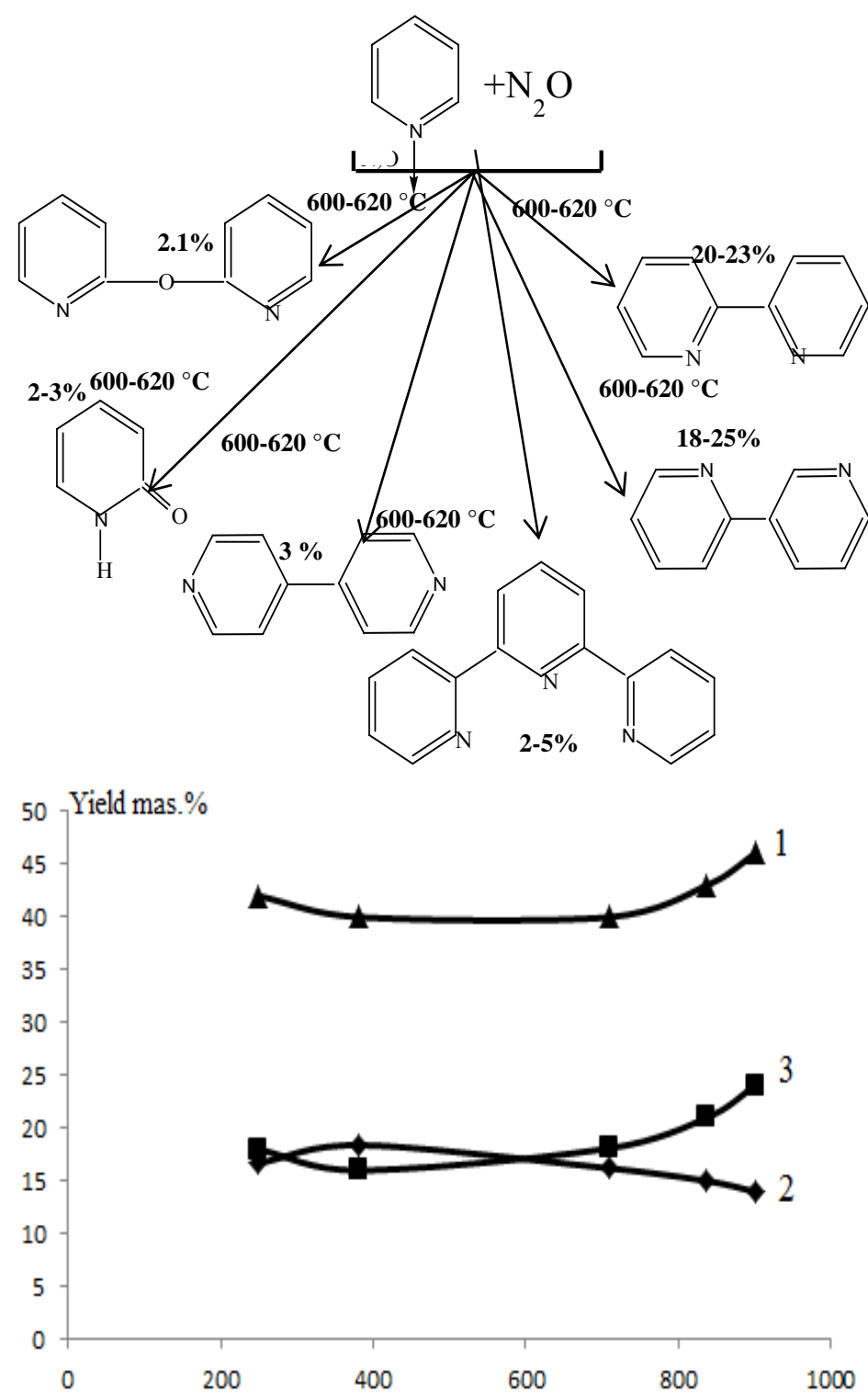

Fig. 3 The influence of vol. rate of $\mathrm{N}_{2} \mathrm{O}$ supply on yield of the reaction products: conversion (1), 2,2-dipyridyl (2), 2,3-dipyridyl (3), $\mathrm{T}=600{ }^{\circ} \mathrm{C}$, rate of supply of $\mathrm{P}-0.948 \mathrm{~h}^{-1}$.

\section{References}

[1] Nagiev, T. M. 1989. Chemical Conjugation. Moskva: Nauka.

[2] Nagiev, T. M. 2001. Synchronous Interaction Reaction in Chemistry and Biology. Baku: ELM.

[3] Nagiev, T. M. 2007. Coherent Synchronized Oxidation by Hydrogen Peroxide. Amsterdam: Elsevier.

[4] Nagiev, M. F., Nagiev, T. M., Babaev, R. M., and Tagieva, Ch. A. 1973. "Homogeneous Dehydrogenation of Hydrocarbons with Nitrous Oxide." Azerb. Chem. Journal 5-6: 3-7.

[5] Nagiev, M. F., Nagiev, T. M., and Poladova, L. M. 1975. "Poladova L. M. Research Dehydrogenation Reaction of
Cyclohexene with Nitrous Oxide.” Azerb. Chem. Journal 2: 9-13.

[6] Nagiev, M. F., Nagiev, T. M., and Poladova, L. M. 1975. "Research Dehydrogenation Reaction of Cyclohexene with Nitrous Oxide." Azerb. Chem. Journal 3: 3-5.

[7] Nagiev, T. M., and Tagieva, Ch. A. 1978. "Research Butylene Dehydrogenation with Nitrous Oxide." Azerb. Chem. Journal 5: 7-11.

[8] Nagieva, I. T., Ali-zadeh, N. I., Valiyeva, T. G., and Nagiev, T. M. 2015. "Coherent-synchronized Oxide-tion of Pyridine with Nitrous Oxide to 2,2-and 2,3-dipyridyl." Presented at the 19th European Symposium on Organic Chemistry. Lisboa, Portugal. 